\title{
ANNOUNCEMENTS
}

\section{London 2021 GAC-MAC Joint Annual Meeting Workshops and Short Courses}

\author{
Roberta L. Flemming \\ Department of Earth Sciences \\ Western University, London, Ontario, N6A 5B7, Canada \\ E-mail:rflemmin@uwo.ca \\ bttps:/ /www.gacmac2021.ca
}

\section{ONE DAY WORKSHOPS OR SHORT COURSES Saturday May 15 or Sunday May 16, 2021}

\section{Gaming the Earth: Geoscience Applications of Game Engines, Augmented Reality, and Virtual Reality}

Organizers: Rob Harrap (Queen's University), Jean Hutchinson (Queen's University), David Bonneau (Queen's University), Paul-Mark DiFrancesco (Queen's University)

1-day pre-meeting short course - Saturday May 15, 2021 Visualization, model building, and simulation in the geosciences traditionally rely on software tools like GIS, mining and geophysical visualization packages, custom code in environments like MATLAB, and custom tools created for specific tasks such as rockfall simulation, groundwater modelling, and the like. While many of these tools are powerful, custom built tools tend to emphasize one aspect of a situation. With the increasing power of game engines - which after all have to be able to represent 3-D environments and simulate phenomena such as smoke, fire, and explosions to be engaging researchers have begun to apply these engines as general-purpose platforms for geoscience needs.

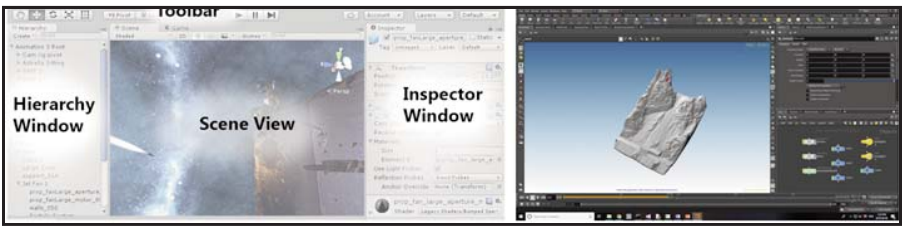

Two examples from screen shots, illustrating software that can be adapted for geoscientific problems.

These tools also strongly support multiple interaction modes from touch screen to augmented reality to virtual reality, all flexibly using the same world model. Recent events have led to dramatically increased interest in how to interact with geological spaces remotely, whether for education or research communication needs, and game environments handle this very well. This course will cover the range from simple model construction in the Unity game engine, through applications in geoscience education and simulation. We will also cover the construction of game objects from LiDAR or photographs, the use of online assets, plug in tools to solve specific needs such as terrain shaping, and other practical issues in making projects happen. Hands on exercises with real-world data will be emphasized.

Intended audience: Industry, Government and Academic Researchers, Students, Educators (K-12)

\section{Rates and Dates: Dating Methods and Applications}

Organizers: Eva Enkelmann (University of Calgary) and William Mattews (University of Calgary)

1-day pre-meeting virtual short course - Saturday May 15, 2021

The objective of this one-day course is to introduce geoscientists to the fundamentals of radiometric dating techniques. Geo- and thermochronology techniques allow scientists to quantify the timing of geological events and with this the duration and rates of geological processes. These methods differ in their sensitivity to temperatures ranging from mineral crystallization at $>800^{\circ} \mathrm{C}$ to upper crustal heating and cooling at 50$100^{\circ} \mathrm{C}$. This one-day short course will provide the principles of radiometric dating. Emphasis will be given to geochronology and thermochronology methods such as U-Pb, Ar-Ar, UTh/He, and fission track dating, and the possibilities to combine multiple methods on individual samples and single grains. Focus will be given to practical aspects that will allow scientists to choose the best method, conduct sampling in the field and core storage facilities, and project budgeting for a wide range of applications.

Topics covered in this short course:

- Differences between geo- and thermochronology

- Basics of the U-Pb, fission track and U-Th/He methods

- Application of geochronology to various geological settings

- Applications of low-temperature thermochronology

- Common tools for data analyses, data presentation and interpretation

- Use of multi-method, single-grain analyses

- Sampling strategies, what and how to sample, budget, and time considerations

Intended audience: Industry, Government and Academic Researchers, Students 


\section{Quantifying Sediment Provenance and Basin Thermal Histories}

Organizers: Eva Enkelmann (University of Calgary) and William Mattews (University of Calgary)

1-day pre-meeting virtual short course - Sunday May 16, 2021

The objective of this one-day course is to introduce geoscientists to the fundamentals of radiometric dating techniques and their use in studying sediment basins. New developments in geo- and thermochronology techniques allow effectively dating large quantities of individual grains and the application of multiple methods on single grains. This offers to answer a wide range of geological questions regarding sedimentary basins. These include: 1) sediment provenance and identify sediment recycling; 2) reconstructing the tectonic evolution of the sediment source region; 3) quantifying maximum and minimum temperature of sediment burial; 4) quantifying timing and rate of basin inversion; 5) determining sediment deposition age; 6) quantifying amount of removed sediment strata or tectonic overburden. Focus will be given to practical aspects that will allow scientists to choose the best method, conduct sampling in the field and core storage facilities, and project budgeting and time planning.

Topics covered in this short course:

- Differences between geo- and thermochronology

- Application of geochronology and low-temperature thermochronology to basin strata

- Multi-method dating of detrital minerals

- Common tools for data analyses, data presentation and interpretation

- Thermal history modelling of basin strata

- Sampling strategies, what and how to sample, budget, and time considerations

Intended audience: Industry, Government and Academic Researchers, Students

\section{A New Exploration Model for Silurian Lockport Group "Guelph" Carbonate Plays, Southwestern Ontario and Great Lakes Region}

Organizers: Shuo Sun (Western University; Oil, Gas and Salt Resources Library), Frank Brunton (Ontario Geological Survey, Western University), Jordan Clark (Oil, Gas and Salt Resources Library), and Jisuo Jin (Western University) 1-day pre-meeting workshop - Sunday May 16, 2021

Regional-scale outcrop/subcrop and deeper subsurface mapping by staff/students at Ontario Geological Survey with staff at the Oil, Gas and Salt Resources Library has resulted in the development of a revised stratigraphic nomenclature and paleoenvironmental interpretation for the mature early Silurian petroleum play formerly referred to as the "Guelph" pinnacle play in southwestern Ontario. This predominantly dolostone succession is now referred to as the Lockport Group and comprises, in ascending order: Gasport, Goat Island, Eramosa and Guelph formations. Recognition of subregional disconformi- ties within the revised lithofacies relationships indicate that these stacked carbonate units were deposited on a complex, structurally-influenced, carbonate ramp that dipped towards the Appalachian foreland basin.

This core workshop includes the recent study on regional porosity and permeability variations of these Lockport Group pinnacles and inter-pinnacle areas in southwestern Ontario. Data from cored wells in various depositional regimes will be displayed to show the regional stratigraphic architecture, depositional and diagenetic attributes, and geological controls on porosity and permeability distributions. This workshop will also provide: 1) geo-spatial analysis of the porosity-permeability distributions of the stacked carbonate cycles relative to the re-interpretation of the largely non-reefal pinnacle structures as paleokarstic remnant landforms; 2) descriptions of the reinterpreted paleokarstic rubble that characterizes the dramatically thinner Lockport Group inter-pinnacle settings; 3) case studies of the reef mound cycles in middle to outer ramp areas where paleokarstic features are less well developed. Virtual reality tools are also employed for videos demonstrating the 3$\mathrm{D}$ model of the preserved carbonate structures in the subsurface.

Intended audience: Industry, Government and Academic Researchers, Students, General Public
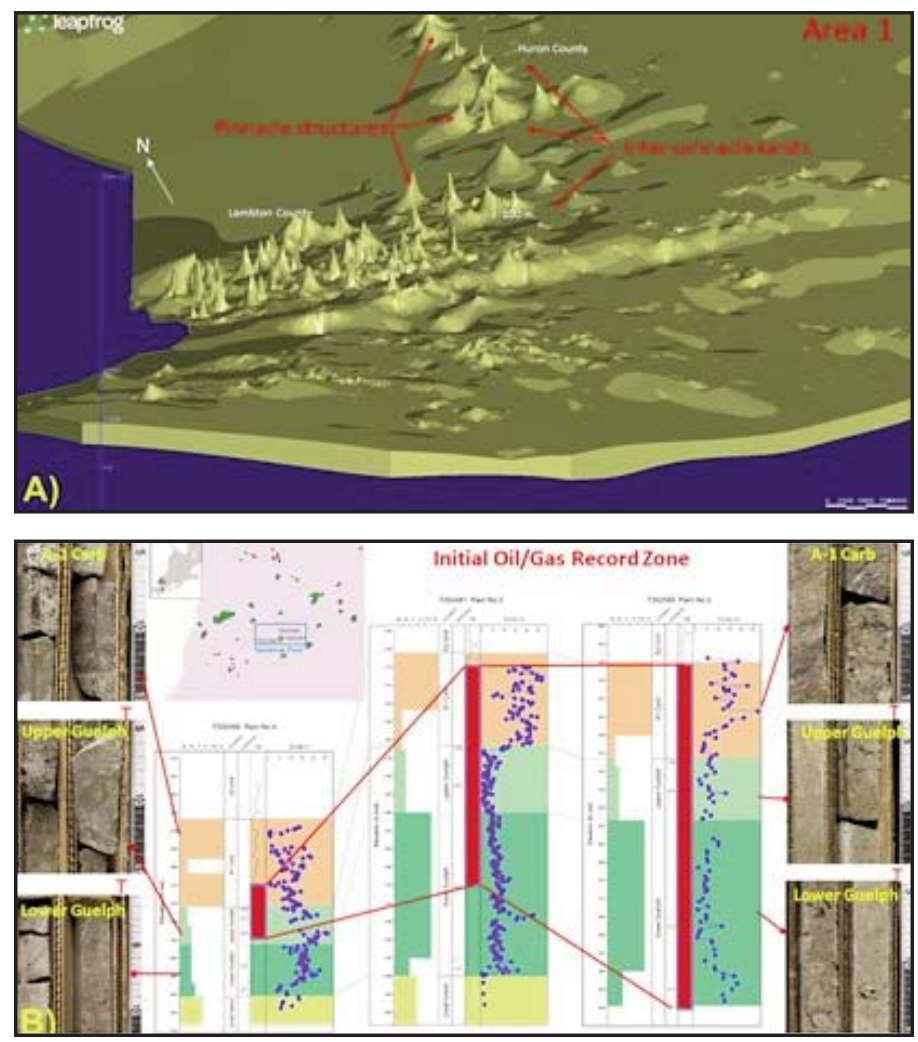

A) A 3-D model image of the pinnacle structures and inter-pinnacle karst areas of the Silurian Lockport Group, southwestern Ontario. Thickness of the pinnacle structures are exaggerated x30. B) An example of the Guelph Formation lithofacies vs. porosity variations in one of the pinnacle plays, southwestern Ontario. These non-reefal lithofacies display various karstic surfaces that are correlative on varying scales. 


\section{TWO-DAY WORKSHOPS OR SHORT COURSES Saturday-Sunday May 15-16, 2021}

\section{Modern Scanning Electron Microscope: The Most Versatile Tool for Geoscience}

Organizers: Réjean Girard and Jonathan Tremblay (IOS Servic-

es Géoscientiques Inc.)

2-day pre-meeting workshop - Saturday May 15 to Sunday May 16, 2021

Although often perceived as the old dusty machine, scanning electron microscopes underwent rapid technological evolution in the last decade that makes them the most powerful tool available to geoscientists. A large array of detectors, fulfilling different functions, can be attached, synchronized and automated, fulfilling various needs such as fast EDS-SDD fully quantitative chemical analysis out-performing an electron microprobe, wavelength-dispersive spectrometry (WDS) for minor element analysis, micro-XRF for trace elements measurement, electron diffraction (EBSD) to reveal the crystalline structure, near-atomic scale TEM imaging, cathodoluminescence imaging and spectroscopy, microtomography or surface ablation for 3-D imaging, QEMSCAN and MLA for automated mineralogy, etc. The workshop aims to familiarize geoscientists with operation of the instruments and its capabilities for their daily research work as well as presenting a series of automated applications and case studies.

Intended audience: Students and Industry, Government or Academic Researchers

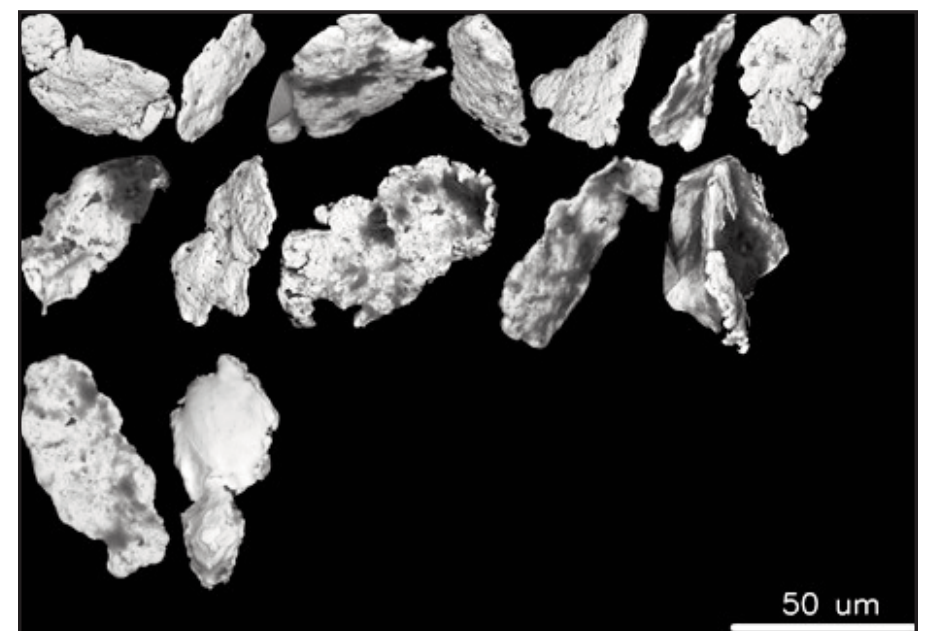

Gold grain mosaic automated routine.

\section{Fluid and Melt Inclusions: Applications to Geological Processes}

Organizers: Matthew Steele-MacInnis (University of Alberta) and Pilar Lecumberri-Sanchez (University of Alberta)

2-day pre-meeting virtual MAC Short Course - Saturday May 15 to Sunday May 16, 2021

The short course will focus on application of fluid inclusions to solve geological problems, and includes talks from world experts in fluid and melt geochemistry applied to hydrocar- bons, diagenesis, metamorphic and igneous processes, Earth's deep interior, and economic mineral deposits.

Lecturers will include:

- Jaques Pironon (University of Lorraine)

- Andras Fall (UT Austin)

- Martin Appold (University of Missouri)

- Omar Bartoli (University of Padua)

- Evan Smith (Gemological Institute of America)

- Jake Hanley (Saint Mary's University)

- Rosario Esposito (Colorado College)

- Matthew Steele-MacInnis (University of Alberta)

- Pilar Lecumberri-Sanchez (University of Alberta)

- Simone Runyon (University of Wyoming)

Intended Audience: Industry, Government and Academic Researchers, Students

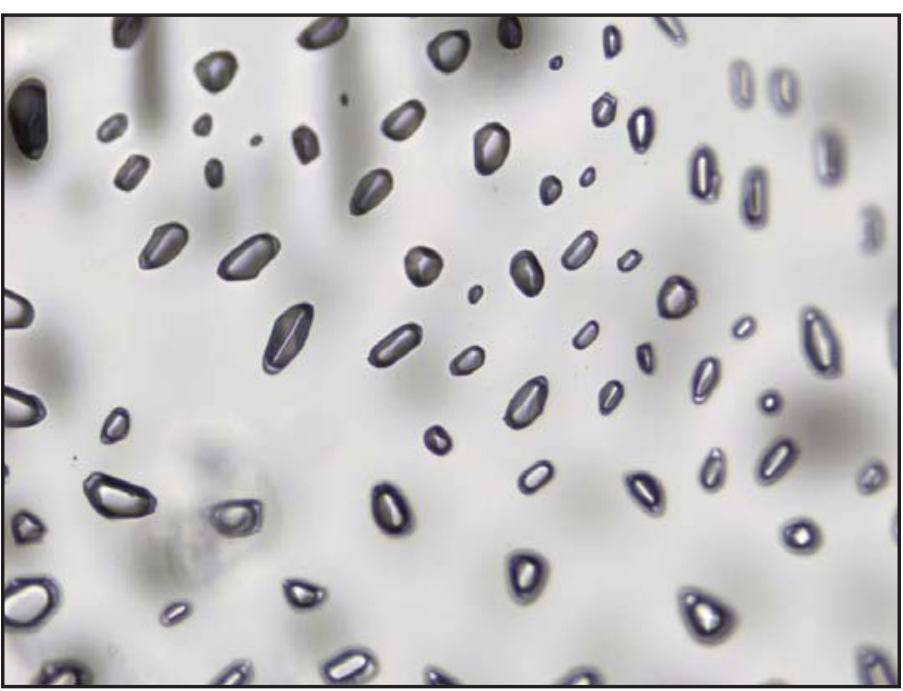

Image shows vapor-rich fluid inclusions in quartz from The Schneckenstein (Germany).

\section{Introduction to Data Analytics and Machine Learning for Geologists}

Organizers: Jessica Stromberg (CSIRO Mineral Resources) and Shawn Hood (Goldspot Discoveries)

2-day pre-meeting virtual workshop - Saturday May 15 to Sunday May 16, 2021

A practical introductory course aimed at geologists in mineral exploration and mining. The participants will be given an overview of modern data analytics methods, including machine learning, illustrated by practical case studies across multiple commodities. There will be exercises using a range of geoscience datasets including geochemistry, geophysics and hyperspectral mineralogy for the participant to practice with the new methods they have learnt. These tutorials will use a diverse range of software, including free machine learning software (KNIME), a Python package for geochemical data analysis (Pyrolite) and CSIRO-developed multiscale wavelet analysis for drill hole data (Data Mosaic). Knowledge of intro- 
ductory statistics and some Python could be useful but is not required.

Instructors:

- Dr. June Hill, CSIRO Mineral Resources

- Dr. Shawn Hood, Goldspot Discoveries

- Dr. Morgan Williams, CSIRO Mineral Resources

- Shervin Azad, MSc, Goldspot Discoveries

- Dr. Jessica Stromberg, CSIRO Mineral Resources

Intended audience: Industry, Government and Academic Researchers

\section{FOUR DAY WORKSHOP - BERRY SCHOOL May 13-16, 2021}

\section{Canadian Powder Diffraction Workshop 14 - Berry School}

Organizers: Roberta Flemming (Western University) and Jim Britten (McMaster University)

4-day pre-meeting workshop - May 13-16, 2021

This workshop is intended for students and practitioners who would benefit from an improved understanding of the basic theory and practice of powder and related X-ray diffraction techniques for analyzing crystalline materials. Sessions will cover the basic theory of powder diffraction, experimental considerations, sample preparation, and data analysis. Examples of some simple and some more difficult powder diffraction, Rietveld, 2-D, and 3-D diffraction analyses will be presented. Other diffraction and scattering techniques will also be presented, appropriate for the characterization of powders, in situ solids, thin films, single crystals, nanostructured and disordered materials. A variety of diffraction software will be introduced during the presentations and used in the afternoon's practical sessions. Several practice data sets will be supplied. Participants are also invited to bring data from their own research to be worked out at the Workshop with expert advice from the Instructors who will be present. There may also be an opportunity to collect diffraction data on various instruments at Western University (if on-site, pandemic permitting). On-site participation in the Workshop will be limited to 40 participants. The workshop is intended to be run in person, but a virtual format will be implemented if necessary (in the event of COVID-19 restrictions).

Intended Audience: Industry, Government and Academic Researchers, Students

\section{GAC-MAC London 2021}

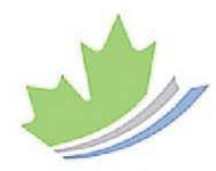

GEOLOGICAL ASSOCIATION
GOLOGIOUE DU CANADA

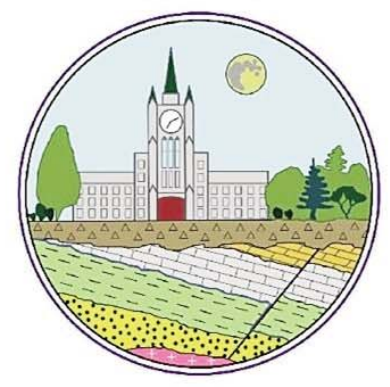

May 17-19, 2021

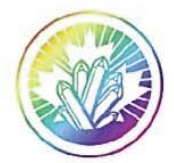

MINERALOGICAL ASSOCIATION OF CANADA MINÉRALOGIQUE DU CANADA

Exploring Geosciences Through Time and Space
Explorer les géosciences à travers le temps et l'espace 